\title{
The Anesthetic Care of an Infant with Congenital Cystic Adenomatoid Malformation
}

\author{
Jennifer M Oakes ${ }^{1 *}$ and Jeffrey L Burks ${ }^{2}$ \\ ${ }^{1}$ Department of Nurse Anesthesia, Virginia Common wealth University, USA \\ ${ }^{2}$ Department of Nurse Anesthesia, University of Colorado-Colorado Springs, Colorado
}

Submission: November 28, 2017; Published: December 14, 2017

*Corresponding author: Jennifer M Oakes, Department of Nurse Anesthesia, Virginia Common wealth, South Dakota, USA, Tel: 605-362-0100; Fax: 605-362-5706; Email: Jennifer.oakes@mtmc.edu

\section{Abstract}

Congenital Cystic Adenomatoid Malformations (CCAM) is a rare and potentially complicated lesion involving one or more lobes of the lung. Mortality rates may be as high as $68 \%$. Often a restrictive breathing pattern is demonstrated [1]. Anesthetic management must take into account the size of the lesion, symptoms, age of patient, and presence of possible associated anomalies. We present this case study of an infant who presented for surgical resection of CCAM at 8 months old. The infant presented with a type 1 congenital lesion in the left lower lobe with no apparent cardiac involvement. The surgical course required one lung strategic ventilation, judicial fluid management and meticulous postoperative observation and management. Surgical resection of the cyst and lobe was successful and post-operative course was notable for restored respiratory function.

\section{Introduction}

Congenital Cystic Adenomatoid Malformation (CCAM) accounts for $25 \%$ of congenital malformations and $95 \%$ of congenital lung lesions [1,2]. The incidence ranges between 1:10,000 and 1:35,000 newborns [3]. CCAM can be diagnosed prenatally using ultrasound examination or post-natally when unanticipated respiratory distress in the neonate is noted, prompting chest radiographs, $\mathrm{CT}$, and/or MRI. The cystic formation usually involves a single lobe of the lung but may occur bilaterally and may include diffuse multilobular involvement $[1,4,5]$. Patients may be asymptomatic or present with acute respiratory distress requiring immediate intervention and management [6]. This article reviews the successful anesthetic management of an eight month old infant, reviews pathophysiology and discusses literature relating to this type of pulmonary lesion.

\section{Case History and Management}

An 8 month old infant boy was diagnosed with CCAM at 26 weeks gestation during a routine ultrasound examination. The cyst was located primarily in the left lower lobe with no definite left upper lobe component and no cardiac involvement. The cyst was an air-filled structure containing septations, oval configuration and measured approximately $2 \mathrm{~cm}$ transverse $\mathrm{x}$ $1.2 \mathrm{~cm}$ anterior to posterior $\mathrm{x} 2.7 \mathrm{~cm}$ superior to inferior, with a small solid component located centrally and extending along the left heart border. Subsequent ultrasound examinations were performed every 2 weeks for the duration of gestation, to monitor growth and compensation of the cyst and surrounding tissues. No hydrops fetalis or growth of tissues was noted throughout these examinations and the pregnancy continued without any further complications. Normal vaginal delivery occurred at 39 weeks 1 day with appropriate APGAR scores. The infant had normal feeding growth and development until the age of 8 months.

At eight months of age the decision was made to proceed with a laparoscopic left lower lobectomy. A mask induction was utilized, with increasing intervals of sevoflurane, a 50/50 mixture of nitrous oxide and oxygen. Two peripheral IV's were placed, along with an arterial line for lab draws and blood pressure monitoring. Propofol, fentanyl, and rocuronium were given for intubation. A Microcuff 3.5 ETT tube was inserted by direct laryngoscopy, and then advanced into the right main bronchus with a fiber optic flexible bronchoscope for confirmation of placement. Breath sounds were confirmed once the patient was in the left lateral position. Tidal volumes of $32-36 \mathrm{ml} \mathrm{(3-4} \mathrm{ml/kg)}$ were achieved with pressure support ventilation and tolerated well by the patient throughout the procedure. Neuromuscular blockade was maintained with the use of rocuronium. $120 \mathrm{mls}$ of $5 \%$ Albumin plus the patient's maintenance fluids of D5LR were given for IV hydration. In the last minutes of the procedure the ETT was pulled back $2 \mathrm{~cm}$ allowing the left lung to inflate and check for air leaks. Neuromuscular blockade was reversed upon removal of laparoscopic instruments, and spontaneous respirations resumed, followed with an eventless extubation. 
The patient was returned to the OR shortly after being admitted into the PICU, due to an abnormal chest x-ray which showed bilateral infiltrates. The infiltrates were presumed to be, possibly caused by a twisted clip used on the bronchi. Upon insertion of laparoscopic instruments the complication appeared to have resolved spontaneously. The remainder of the PICU recovery was unremarkable and follows up chest x-rays improved. Serosanguinous chest tube drainage was minimal and respiratory function was normal. The infant was eventually discharged home after 5 days of observation.

\section{Pathophysiology and Literature Review}

The diagnosis of Congenital Cystic Adenomatoid malformation (CCAM) has three main classifications. Type 1 is the most common type, representing $65 \%$ of all CCAM cases $[2,5,6]$. This is characterized by a cysts of varying sizes measuring more than $2 \mathrm{~cm}$ in diameter. Type 2 lesions represent smaller cysts less than $2 \mathrm{~cm}$ in diameter but usually occur in clusters of multiple small cysts $[5,6]$. Type 3 lesions contain many microscopic cysts which provide a bulky lesion producing large mediastinal shifts. The prognosis and management for type 2 and 3 lesions are less favorable than type 1 . If a mediastinal shift is noted and accompanied by hydrops, mortality can be up to $68 \%$ [1]. The use of CT scan can help differentiate the internal structure of the lesions as being air or fluid filled cysts.

Table 1: Basic types of CCAMs and associated anomalies.

\begin{tabular}{|c|c|c|c|}
\hline Type of CCAM & Size & $\begin{array}{c}\text { Multi lobular } \\
\text { Involvement }\end{array}$ & $\begin{array}{c}\text { Associated } \\
\text { Anomalies }\end{array}$ \\
\hline Type 1 & $3-7 \mathrm{~cm}$ & Not usually & None \\
\hline Type 2 & $0.5-2 \mathrm{~cm}$ & Not usually & $\begin{array}{c}\text { Kidney Agenesis, } \\
\text { pulmonary } \\
\text { Hypoplasia, and } \\
\text { Diaphragmatic } \\
\text { Hernias }\end{array}$ \\
\hline Type 3 & $<0.2 \mathrm{~cm}$ & Yes & $\begin{array}{c}\text { Mediastinal } \\
\text { Displacement, } \\
\text { Hypoplasia, } \\
\text { Polyhydramnios, } \\
\text { Fetal Hydrops }\end{array}$ \\
\hline
\end{tabular}

There are some reports of associated anomalies as they correlate with the type of CCAM in question (Table 1) [6]. Type 1 is not usually associated with any specific anomalies. Type 2 does have some associations, some of which are incompatible with life, such as kidney agenesis, pulmonary hypoplasia, and diaphragmatic hernias. Type 3 has been known to cause mediastinal displacement and hypoplasia of the preserved lung. In addition, this type is highly associated with polyhydramnios and fetal hydrops [6]. The literature does suggest other types of CCAM, but they are atypical and not considered classic presentations therefore they are not a subject of discussion in this article.

The differential diagnosis includes diaphragmatic hernia, pulmonary sequestration, bronchogenic cysts, and congenital lobar emphysema [1]. The most common presentation is respiratory distress of the neonate [4]. With the advancement of ultrasonography, more CCAMs are being detected prenatally. This allows for early planning of interventions and treatment [6]. The presence of the CCAM can lead to different pathological presentations. Respiratory distress is the most common and CCAMs present with a restrictive breathing pattern [2]. In the prenatal period, ultrasound examination may show compression of the heart which may decrease cardiac output by restricting normal heart function [1]. Pressure on the inferior vena cava may decrease preload and venous return to the heart. A mediastinal shift may make ventilation difficult if unassisted and airway management complicated $[2,4]$.

The definitive treatment of CCAM is surgical excision.2Even small cysts that do not impede on mediastinum and cardiac functions can eventually lead to increased risk of pulmonary infection and malignancy [1,5]. Asymptomatic CCAMs may go untreated but may require medical or surgical management later in life [4]. Such cases may present later in life with non-immune mediated cough, hemoptysis and anorexia. If surgical treatment is deemed necessary, opinions vary regarding the ideal time and age that surgical resection should take place. Some feel that in the presence of symptoms, surgery should take place as early as possible in an effort to preserve the normal lung parenchyma $[7,8]$. In the presence of hydrops, fetal intrauterine surgery may be justified [1]. Risks associated with these procedures include premature rupture of membranes, premature birth, hemorrhage, infection and further injury to the fetus.

\section{Discussion}

In this case, diagnosis and preparations were made prenatally which allowed for early testing, measurements and anticipation. The lesion in question was type 1, presenting as a single large cyst. This made surgical resection a more feasible option. There was no hydrops or apparent cardiac involvement. Concerns regarding positive pressure ventilation played a role in our initial management during airway instrumentation. Nitrous oxide was avoided because of possible cyst expansion if air was present within the cyst. Several cases have been reported using thoracic epidural analgesia [9]. Remifentanil infusions have also been reported favorably [10].

\section{Conclusion}

Anesthetic management of an infant with CCAM can be challenging. The type of lesion, cardiac involvement and severity of symptoms must all be taken into consideration in order to provide ideal hemodynamic management and ventilator support. Knowledge of path physiology and potential complications also assists in developing the ideal anesthetic care plan.

\section{Referencces}

1. (2003) Study. The Internet Journal of Advanced Nursing Practice IJANP 5(2).

2. Rosado De Christenson, Stocker JT (1991) congenital cystic adenomatoid malformation. Radio Graphics 11(5): 865-886. 
3. KapralikJ, Wayne C, Chan E, Nasr A (2016) Surgical versus conservative management of congenital pulmonary airway malformation in children: A systematic review and meta-analysis. J Pediatr Surg 51(3): 508-512.

4. Aslan AT, Yalcin E, Soyer T, Dogru D, Talim B, et al. (2006) Prenata period to adolescence: the variable presentations of congenital cystic adenomatoid malformation. Pediatr Int 48(6): 626-630.

5. Cloutier MM, Schaeffer DA, Hight D (1993) Congenital Cystic Adenomatoid Malformation. Chest 103(3): 761-764.

6. Dos reis AR, Ribeiro FB, Schultz R (2015) Congenital cystic adenomatoid malformation type I. Autops Case Rep 5(3): 21-26.

7. Ferreira HP, Fischer GB, Felicetti JC, Camargo Jde J, Andrade CF (2010) Surgical treatment of congenital lung malformations in pediatric patients. J Bras Pneumol 36(2): 175-180.
8. Polites SF, Habermann EB, Zarroug AE, Thomsen KM, Potter DD (2016) Thoracoscopic Vs open resection of congenital cystic lung disease- utilization and outcomes in 1120 children in the United States. J Pediatr Surg 51(7): 1101-1105.

9. Guruswamy V, Roberts S, Arnold P, Potter F (2005) Anaesthetic management of a neonate with congenital cyst adenoid malformation. Br J Anaesth 95(2): 240-242.

10. Hugh D, Cameron B (2009) Anesthetic management of a neonate with a congenital cystic adenomatoid malformation and respiratory distress associated with gross mediastinal shift. Paediatr Anaesth 19(3): 272-274.

\section{Your next submission with Juniper Publishers will reach you the below assets}

- Quality Editorial service

- Swift Peer Review

- Reprints availability

- E-prints Service

- Manuscript Podcast for convenient understanding

- Global attainment for your research

- Manuscript accessibility in different formats ( Pdf, E-pub, Full Text, Audio)

- Unceasing customer service

Track the below URL for one-step submission https://juniperpublishers.com/online-submission.php 